\title{
Las microfinanzas rurales en Colombia y el proceso de financiarización: un estudio de caso
}

\author{
Natalia Ramírez-Virviescas* \\ Diego Guevara-Castañeda**
}

Fecha de recepción: 17 de julio de 2020

Fecha de aprobación: 30 de noviembre de 2020

Resumen: El crecimiento desregulado de las microfinanzas representa una amenaza para la sostenibilidad y materialización de su misión. El presente artículo busca ahondar en el desarrollo de las microfinanzas rurales en Colombia, yendo más allá del análisis de inclusión financiera. Con este propósito, se aplica el método de investigación cualitativo, que se integra con la revisión de los índices financieros relacionados con la oferta de microcrédito al sector rural colombiano. De manera complementaria al estudio de alcance nacional, se realiza y analiza la Encuesta sobre uso de productos y servicios microfinancieros en zonas rurales 2018, con el fin de profundizar en la percepción local y regional sobre los servicios microfinancieros en siete municipios pertenecientes a las categorías 4, 5 y 6 de los departamentos de Boyacá y Santander. Tal análisis permite evidenciar que las microfinanzas rurales no son per se una solución para la pobreza, pero sí se consolidan como un instrumento a partir del cual se viabilizan y se hacen sostenibles las iniciativas productivas del campo colombiano, por lo cual sirven como herramienta complementaria a las políticas para el desarrollo rural.

Palabras clave: microfinanzas; financiarización; pobreza rural; población rural; inclusión financiera; economía agraria; desarrollo agrícola; política agraria.

Clasificación JEL: G21, G32, Q14, R51, D92

Como citar este artículo:

Ramírez-Virviescas, N., \& Guevara, D. (2021). Las microfinanzas rurales en Colombia y el proceso de financiarización: un estudio de caso. Apuntes Del Cenes, 40(71) Págs. 219 - 252. https://doi.org/10.19053/01203053.v40. n71.2021.11466

\footnotetext{
Economista y magíster en Ciencias Económicas Universidad Nacional de Colombia. nramirezv@unal.edu.co (iD https://orcid.org/0000-0002-3024-6154

** Profesor Escuela de Economía Universidad Nacional de Colombia. Doctor en Ciencias Económicas. dieguevarac@ unal.edu.co (iD https://orcid.org/0000-0003-4018-7095 Contacto de correspondencia.
} 


\title{
Rural Microfinance in Colombia and Financialization Process: A Case Study
}

\begin{abstract}
The deregulated growth of microfinance represents a threat to the sustainability and fulfillment of its mission. This paper aims to analyze the development of rural microfinance in Colombia, going beyond the study of financial inclusion. With this purpose, a qualitative research method is applied together with the review of financial indexes related to the offer of microcredits to the Colombian rural sector. In addition to the national study, Survey on the use of microfinance products and services in rural areas 2018 was carried out and analyzed for deepening in the local and regional perception of microfinance services in seven municipalities belonging to the categories 4, 5 and 6 of Boyacá and Santander states. Throughout this analysis, it is evidenced that rural microfinance is not per se a solution for poverty, but it is consolidated as an instrument through which the productive initiatives of the Colombian countryside could be viable and sustainable, which is why they serve as a complementary tool of rural development policies.
\end{abstract}

Keywords: microfinance; financialization; rural poverty; rural population; financial inclusion; agricultural economics; agricultural development; agricultural policy. 


\section{INTRODUCCIÓN}

El sector rural colombiano enfrenta desafíos estructurales que deben ser superados en busca de mejorar la productividad y competitividad del campo del país. Según el Departamento Administrativo Nacional de Estadística (DANE), alrededor de 5249317 de pobladores rurales colombianos soportan múltiples privaciones en salud, educación y nivel de vida (DANE, 2017). Tal incidencia de la pobreza en los municipios rurales se explica en gran medida porque el presupuesto público destinado al sector rural en Colombia es insuficiente para atender las necesidades de los campesinos; además, la precaria infraestructura dificulta el desarrollo socioeconómico de las comunidades campesinas y atenta contra la competencia de sus emprendimientos productivos, por lo que tales índices van acompañados por el bajo ritmo de crecimiento de la productividad sectorial y la baja competitividad del sector agropecuario (Misión para la Transformación del Campo, 2015).
Reconociendo que uno de los principales obstáculos para el adelanto y la sostenibilidad de iniciativas productivas rurales es el limitado acceso a financiamiento formal -de acuerdo con Estrada et al. (2015), el índice de bancarización rural promedio fue de $3.2 \%$ en $2010 \mathrm{y}$ en 2012 alcanzó apenas el $4.2 \%$-, el Gobierno ha desarrollado estrategias de inclusión financieral que van de la mano con el ingreso al mercado de entidades que operan en zonas rurales, con población que no accede a financiamiento por otras vías, con el objetivo de promover programas que buscan enfrentar el restringido crecimiento y la baja competitividad.

Frente al desenvolvimiento de las microfinanzas rurales, en Colombia se debe mencionar que, a pesar de estar bajo directrices estatales, estas se han dado de manera independiente. Se puede apreciar que en el país no se han empleado como herramienta política para superar la pobreza, sino como complemento a las mismas. Por lo tanto, han sido proyectos privados

1 La Estrategia Nacional de Inclusión Financiera 2016 maneja recursos concedidos por Finagro en representación del Fondo de Microfinanzas a instituciones financieras, y asociaciones elegibles. 
los que han configurado el sistema de microfinanzas rurales en Colombia, con el interés de servir como mecanismo del desarrollo rural.

Aunque los programas y proyectos de microfinanzas enfocados en el sector agropecuario en Colombia surgieron con el propósito de potenciar el crecimiento del sector y así alcanzar mejores niveles económicos y sociales, la vocación altruista no es el común denominador de las entidades prestadoras de los microcréditos. Para ciertas entidades la misión inicial de las microfinanzas rurales se ha ido desdibujando y ha evolucionado hacia una lógica de máxima rentabilidad, tal como lo han analizado Bateman (2013) y Stiglitz (2012) al exponer una visión crítica frente a la explotación de la base de la pirámide.

Así las cosas, resulta importante analizar si factores propios de la financiarización ${ }^{2}$ como concepto pueden ser extrapolables a las microfinanzas, y en tal caso poder proponer un nuevo término: microfinanzas financiarizadas, es decir, a servicios financieros de bajo monto, caracterizados por métodos de cobranza intimidantes, empleo de tasas de interés que superan la tasa de usura, carencia de acompañamiento o apoyo al usuario y desvinculación del propósito productivo, progresivo e inclusivo.
Dada la importancia de las microfinanzas para el avance rural y reconociendo las amenazas que puede llegar a representar el crecimiento desregulado de su sistema, el objetivo de esta investigación consiste en analizar el desenvolvimiento actual de las microfinanzas rurales en Colombia para reconocer si se presentan aspectos de vulnerabilidad que conlleven un proceso de financiarización $y$ su consecuente impacto negativo en el desarrollo del sector. De esta manera, se busca proponer un nuevo concepto que, basado en la evidencia de los entornos rurales colombianos, permita hacer un análisis profundo de las oportunidades y problemáticas que representa la expansión del microcrédito rural en el país.

Inicialmente, este documento presenta una revisión de literatura, explora la dinámica de las microfinanzas en cuanto a sus aportes y sus aspectos problemáticos, analizando tanto su definición como su origen. Después estudia las microfinanzas rurales en Colombia, para lo cual se repasan estadísticas $\mathrm{y}$ estudios disponibles que permiten reconocer características de financiarización dentro de su desarrollo. Para ello se emplearon como variables de estudio los índices de bancarización, tasas de interés de las instituciones que ofrecen microcréditos al sector rural colombiano, entre otros. Adicionalmente se presenta la Encuesta sobre uso de productos y servicios microfinancieros

2 Se adopta el concepto de financiarización dado por Sawyer (2014), haciendo referencia al crecimiento del sector financiero en sus operaciones, poder, mecanismos, entre otros, el cual genera la reconcentración de los ingresos a favor de los tenedores de capital e inestabilidad financiera y económica. 
en zonas rurales 2018, realizada con el fin de ahondar en la percepción local y regional sobre los servicios microfinancieros. En último término, se presentan algunas conclusiones y recomendaciones para promover mayor regulación sobre las microfinanzas rurales.

\section{UNA MIRADA A LAS MICROFI- NANZAS: APORTES Y ASPECTOS PROBLEMÁTICOS}

Las microfinanzas integran la oferta de servicios financieros que contemplan acceso a microcréditos, seguros, sistemas de ahorro e incluso transferencias de fondos, dirigidos a las personas de bajos ingresos que normalmente se encuentran fuera del sistema financiero formal. Inicialmente, fueron concebidas con el fin de brindar recursos de capital que permitieran fomentar la vocación productiva de aquellos en condición de pobreza en el mundo, es por esto que su desarrollo se ha llevado a cabo en los países emergentes como una estrategia de inclusión financiera y económica (Armendáriz, 2013).

En este sentido, la implementación de programas de microfinanzas rurales constituye una estrategia para el mejoramiento de las condiciones de vida de las personas en situación de pobreza en el campo, mas no una solución estructural a la misma. Estos servicios se presentan como una herramienta que facilita a las personas en dicha condición el acceso a recursos económicos a través de mecanismos de crédito adaptados a las condiciones y requerimientos puntuales de cada población, permitiendo entre otros la reducción de las condiciones de vulnerabilidad asociadas a la pobreza, al promover el aumento en los niveles de ingreso y de consumo de los hogares $\mathrm{y}$ de esta forma el empoderamiento necesario para la toma de decisiones económicas responsables (Perossa \& Marinaro, 2014).

Las microfinanzas operan en el borde entre filantropía y negocio. En el mundo, el incremento de los programas de microfinanzas ocasiona una saturación del mercado, lo cual ha dado lugar a una expansión desregulada que desencadena problemáticas como la ocurrida en India en 2010, que ocasionó inestabilidad a la población y sensación de desconfianza entre los inversionistas y donantes de los programas de microfinanzas (Alfonso, 2015).

En la India, la forma común de ayuda crediticia a la población en situación de pobreza correspondía a los Self Help Groups (SHG), grupos cooperativos de catorce miembros que se organizaban para ahorrar y pedir préstamos. El Estado de Andhra Pradesh, mayoritariamente rural, concentraba a principios de siglo más de la mitad de los SHG del país y la industria microfinanciera antes de 2010 crecía de manera exponencial (Alfonso, 2015). No obstante, a partir del crecimiento acelerado de las instituciones de microfinanzas, seguido por una fuerte caída provocada por el incremento de la competencia entre las 
instituciones, condujo al desconocimiento de las condiciones y prioridades de los clientes más pobres, situación que los llevó a una condición de sobreendeudamiento (Das, 2013).

Maes y Reed (2012) señalan que cerca del $83 \%$ de los clientes de microfinanzas del Estado de Andrah Pradesh habían obtenido préstamos de más de una fuente y muchos de ellos tenían cuatro o más préstamos al mismo tiempo, lo cual causó el incumplimiento de las obligaciones e incluso ocasionó que más de 200 deudores de muy bajos ingresos se suicidaran a finales de 2010. El impulso por el crecimiento llevó a que se emplearan nuevas técnicas de recobro, a tal punto que numerosas declaraciones de clientes de una organización denominada SKS y de sus familiares señalan que los trabajadores de la organización les sugerían de manera explícita a los deudores la idea de suicidarse, tal sugerencia también surgía del grupo en un marco de presión social excesiva y falta de comprensión al beneficiario moroso (Alfonso, 2015).

En concordancia con Beachemin (2010), en países como India, Bosnia o Sudáfrica no hay evidencia de que los más desfavorecidos percibieran algún tipo de cambio sustancial en su calidad de vida, mientras que la rentabilidad y el tamaño de muchas instituciones microfinancieras aumentó en gran medida. Polanco (2011) explica que la debilidad de los efectos de las microfinanzas sobre las poblaciones más vulnerables se encuentra en la mutación de las instituciones microfinancieras hacia organizaciones mercantiles, orientadas a la búsqueda de ganancias, que tienden a tener mayores costos y a aplicar tasas de interés más altas.

Bateman (2013) sugiere que las microfinanzas han llegado a constituirse como una intervención antidesarrollo que profundiza la pobreza, la inequidad y el rezago en el ámbito regional. Además, ciertos esquemas de microfinanciamiento destruyen la capacidad de aumentar la productividad $\mathrm{y}$, en consecuencia, la oportunidad de tener un desarrollo sostenible que garantice la reducción de la pobreza y el crecimiento a largo plazo. Además, la presión o cabildeo que las instituciones microfinancieras ejercen sobre los parlamentos es muy fuerte para eliminar los topes a las tasas de interés, es decir, promueven la eliminación del control de precios para dejar al libre mercado las acciones del sistema microfinanciero.

Los aspectos señalados conforman la definición de microfinanzas financiarizadas en este documento, esto es, la conversión de los servicios microfinancieros en algo netamente rentístico, en donde se desdibuja la metodología microfinanciera $\mathrm{y}$, en consecuencia, se crean escenarios de sobreendeudamiento, cobros por encima de la tasa de usura, acciones coercitivas para la recolección de cartera, entre otros 
aspectos que desencadenan una mayor vulnerabilidad económica y social de la población.

Tal concepto se fundamenta en un proceso de crecimiento descontrolado de la oferta de servicios microfinancieros en manos de instituciones financieras reguladas y de carácter comercial, orientadas específicamente hacia el aumento de la rentabilidad, que conlleva, tal como lo señala Bonizzi (2014), escenarios de inestabilidad financiera y económica.

La definición de microfinanzas financiarizadas surge de la falta de intención de impacto social por parte de ciertos prestatarios y la vulnerabilidad de los clientes, lo cual desvirtúa la utilidad de los servicios financieros, representada cuando se emplean de manera adecuada. En tal sentido, siguiendo a Hudon y Sandberg (2015), el uso de técnicas inadecuadas por parte de las entidades prestadoras de servicios da lugar a que se desdibuje su habilidad para aliviar la pobreza.

Los aspectos problemáticos del sistema microfinanciero evidencian un proceso de financiarización, al estar relacionados con la vinculación de las instituciones microfinancieras con rentistas financieros, que observan en las capas más bajas de la población un gran núcleo de generación de ganancias que se conecta con los círculos financieros mundiales. Bateman (2013, p. 8) señala que, por sugerencia de entidades mul- tilaterales, “(...) el modelo original de microfinanzas subsidiadas del Grameen Bank fue paulatinamente eliminado y reemplazado por el nuevo modelo comercializado (...)". En concordancia con ello, Guevara y Zambrano (2017) advierten que han emergido multinacionales financieras que han innovado en sus portafolios de servicios microfinancieros, ofreciendo una diversa gama de microcréditos para consumo, libre inversión, microseguros y compras a plazos microfinanciadas por canales poco convencionales, como el pago de servicios públicos.

El nuevo panorama de las microfinanzas se hace atractivo para los inversionistas de capital del mercado de valores, tal como lo ilustra el caso de Compartamos en México, el cual pone de presente la manera en que la incursión al mercado de valores de las instituciones microfinancieras ha hecho que sus papeles distorsionados se hayan convertido en uno de los títulos valores más apetecidos por los diferentes inversionistas y especuladores del mundo, deformando la misión de las instituciones microfinancieras sobre su papel en la reducción de la pobreza. México se convirtió en un caso excepcional al sostener más de cinco préstamos por cliente, igual de preocupante que el número de préstamos, es el uso de los mismos, ya que de acuerdo con el estudio presentado por Butcher y Galbraith (2015), la mayoría de las compras financiadas por los préstamos correspondían a ítems simples que pueden ser considerados 
como necesidades básicas, mas no estaban relacionados con inversión productiva, motivo con el cual se ofrecían los microcréditos.

En tal sentido, el propósito de promover la competitividad y productividad por medio de los microcréditos queda desvirtuado, al ser enfocados hacia el consumo por parte de individuos sobreendeudados. Es precisamente el caso de Compartamos el que empieza a suscitar las críticas por parte de diferentes académicos sobre las falencias éticas de las microfinanzas (Hudon \& Sandberg, 2013). Un aspecto determinante es que el mercado microfinanciero mexicano está compartido casi exclusivamente por cuatro organizaciones: Citigroup, Wal-Mart, Banco Azteca y Compartamos. Al existir tan poca competencia, estas instituciones se pueden permitir cobrar intereses usureros a la población, entre el $50 \%$ y el $100 \%$, con el argumento de que su afán de expansión financiera responde a una necesidad para poder luchar contra la pobreza a mayor escala (Alfonso, 2015).

Los casos mencionados ponen de presente la laxa regulación financiera sobre temas microfinancieros, que da lugar a prácticas éticamente cuestionables, fundamentalmente cuando se enmarca la actividad de la institución bajo el único propósito del crecimiento, a fin de aumentar la rentabilidad de los inversores. Esto se explica por la reputación altruista de las microfinanzas, que ha evitado no solo la evaluación y regulación, sino las críticas y el control.

Entre los principales aspectos problemáticos de los microcréditos se destacan las fallas en su asignación, ya que los programas de microcrédito no están siendo dirigidos a la capa más baja de la población, sino a un sector de clase media y media baja. Además, un mismo programa de microfinanzas beneficia en mayor medida a los menos pobres (Hernández et al., 2014). En parte, esta condición se ha debido a que, ante la necesidad de obtener una mayor rentabilidad, las instituciones microfinancieras han elevado el monto de sus préstamos orientando sus servicios a segmentos de la población con mayores ingresos. Con las mismas motivaciones, tal como lo señala Polanco (2011), tales entidades han optado por diferenciar sus productos con el fin de obtener poder de mercado e imponer tasas más altas.

De esta manera, al adoptar el concepto de financiarización asociado al incremento del rol de los actores y motivos financieros en una economía (Guevara \& Zambrano, 2017), el descrito panorama de las microfinanzas ilustra un proceso de financiarización en el que el esquema de microcréditos grupales, en el marco de organizaciones sin ánimo de lucro, ha venido siendo reemplazado por esquema de microcréditos y demás productos individuales y diversificados a favor de los rentistas financieros, cuyas utilidades dependen del pago 
cumplido de las deudas adquiridas por los sectores con mayor vulnerabilidad o por programas que responden a los criterios de mercado establecidos por las instituciones financieras tradicionales, ofreciendo productos y servicios diseñados para la población menos riesgosa, es decir, aquellos con mayor grado de estabilidad económica demostrable o con garantías de respaldo a sus obligaciones (Bonilla, 2016).

Contrario a la situación de India y México, la regulación ecuatoriana ha configurado un buen ejemplo de microfinanzas no financiarizadas. En respuesta a la crisis financiera de 1998 y 1999, la Superintendencia de Bancos y Seguros de Ecuador expidió una serie de leyes con el propósito de tener al sistema financiero controlado, introduciendo límites a las tasas tanto para los créditos como para los depósitos y así evitar la especulación con la tasa de interés. Luego de que en 2007 se reportara que la tasa de interés real estaba siendo en promedio de $108 \%$, lo cual en lugar de asistir a la pobreza la profundizaba, el Gobierno ecuatoriano introdujo medidas que llevaron a que la tasa bajara gradualmente a $37 \%$. De esta manera, los techos para las tasas de interés, las medidas de protección al consumidor y los incentivos para fondos locales permitieron la consolidación de uno de los sistemas microfinancieros mejor regulados en el mundo, en términos de protección al consumidor y restricción a los excesos del mercado microfinanciero (Butcher \& Galbraith, 2015).
Siguiendo a Butcher y Galbraith (2015), los límites a las tasas de interés en Ecuador, considerando los altos costos de operación, han promovido la administración de utilidades coherentes con los fines de las instituciones microfinancieras, además han forzado a las instituciones microfinancieras a ser lo más eficientes posibles para cubrir los costos operacionales. Tales límites desincentivan el ingreso de especuladores financieros que buscan altas rentabilidades de los pobres.

Por otra parte, quienes desaprueban este tipo de medidas argumentan que desincentivan la competencia e incrementan la proliferación de prestamistas informales e incluso ilegales; no obstante, el caso ecuatoriano ilustra los efectos positivos de esta medida, al presentar otras alternativas institucionales para competir generando utilidades razonables; adicionalmente, se ha impulsado la transparencia en la industria microfinanciera por medio de estrictos requerimientos que prohíben cobros adicionales; finalmente el establecimiento de controles y monitoreo ha prevenido las actividades de crédito ilegales. Equivalentemente, en Bolivia la fuerte supervisión ha permitido que se presente la menor tasa de interés en Latinoamérica, al ser aproximadamente igual al $20 \%$ en promedio, gracias a los límites establecidos y a los subsidios de crédito provenientes del Gobierno (Butcher \& Galbraith, 2015). Pese a la efectiva regulación y supervisión, el papel de las microfinanzas no ha lle- 
gado a consolidarse como una fuerza positiva para el desarrollo de las economías mencionadas.

\section{MICROFINANZAS RURALES EN COLOMBIA}

De acuerdo con Finagro (2017), el promedio del índice de bancarización rural pasó de $3.2 \%$ en el año 2010 a $4.2 \%$ en el año 2012 , sin embargo, las zonas rurales son las de menor inclusión financiera. Los resultados del Censo Nacional Agropecuario (CNA-2014) permiten evidenciar la problemática frente al acceso al financiamiento rural, el $50.8 \%$ de las unidades de producción agrícola (UPA) en el área rural dispersa con crédito solicitado, se encuentran en los departamentos de Nariño, Cauca, Boyacá y Santander, lo cual refleja que los restantes 28 departamentos presentan un limitado acceso a crédito. Es importante señalar que para el año 2013 solo el $11 \%$ de las UPA solicitaron crédito para el desarrollo de las actividades agropecuarias y fueron aprobadas el $89.8 \%$ de las solicitudes, destinándose principalmente a compra de insumos, pago de mano de obra, compra de animales, instalación de cultivo, y tan solo el $4 \%$ fue destinado a maquinaria agrícola (Castro, 2016).

Ante el panorama de baja bancarización, Achury (2017) indica que las microfinanzas rurales son un mecanismo de inclusión que ofrece un impacto social a través de la posibilidad de incorporar a la economía formal a personas que no tienen las garantías suficientes para ingresar al sistema financiero tradicional.

En el caso particular de las microfinanzas rurales en Colombia, de acuerdo con Mondragón (2017) fue hasta comienzos de la segunda década del siglo XXI, luego de que entidades no microfinancieras decidieran abrir su segmento a créditos de bajo monto, porque se percataron de la rentabilidad que brinda la rotación, que las entidades microfinancieras con vocación social empezaron a migrar al tema rural, donde la tarea de inclusión aún estaba pendiente. Desde entonces se empieza a discriminar entre urbano y rural en el tema microfinanciero colombiano.

Muchas entidades microfinancieras, como en el caso de Bancamía (2017), realizaron tal expansión a través de la metodología en espiral, envolviendo la ciudad para ver en dónde había cinturones que se pudieran atender $y$ adaptando la tecnología microcrediticia a la nueva realidad rural. Posteriormente, entidades públicas como Finagro, entendiendo que se debe propender a la innovación de productos financieros que superen los establecidos por la banca tradicional y que cuenten con mayor flexibilidad para la atención del sector rural específicamente, promovieron que el Congreso expidiera la Ley 1731 de 2014, mediante la cual se crea el Fondo de Microfinanzas Rurales administrado por Finagro con el fin de estimular la economía rural. 
Con el microcrédito rural, Finagro buscaba aumentar los niveles de inclusión financiera de la población residente en las áreas rurales del país, como instrumento de mejoramiento de los ingresos de la población desatendida por el sistema financiero convencional. Para ello contaba con el Fondo de Microfinanzas Rurales y la Línea de Microfinanzas que se otorgaba a través del sistema financiero convencional (Finagro, 2017).

El Fondo de Microfinanzas Rurales corresponde a recursos concedidos por Finagro en representación del Fondo de Microfinanzas a instituciones financieras, cooperativas y asociaciones elegibles que operan en zonas rurales de Colombia con población que no accede a financiamiento por otras vías. De esta manera, a través de estas instituciones microfinancieras son colocados a los pequeños productores agropecuarios y a micro, pequeñas y medianas empresas que realizan sus actividades en las zonas rurales de Colombia, créditos por un monto máximo de 25 salarios mínimos mensuales legales vigentes, tal como lo estipula la Ley 590 del 2000.

Estos esfuerzos en conjunto, tanto públicos como privados, han permitido que el sistema financiero tenga presencia en el $100 \%$ de los municipios colombianos a través de oficinas o corresponsales bancarios, los cuales son el canal apropiado para las transacciones pequeñas de los servicios microfinancieros. Adicionalmente, las cifras del Banco Agrario señalan que para julio de 2017 tenían cerca de 1,9 millones de clientes de zonas rurales, lo que permitía que el indicador de inclusión financiera fuera igual al $20.14 \%$.

No obstante, tal cobertura no implica la aplicación de tecnología necesaria para incentivar que la presentación de servicios microfinancieros promueva el desarrollo rural, ya que se carece de la aplicación de la denominada metodología microfinanciera, caracterizada por el acompañamiento personalizado a cada usuario. En tal sentido, a pesar de los mayores índices de inclusión financiera, es imperativo propender a la innovación de productos financieros que superen los establecidos por la banca tradicional y que cuenten con mayor flexibilidad para la atención del sector rural. Es por ello que el análisis de la percepción de los habitantes rurales sobre los servicios microfinancieros resulta crucial para entender las dinámicas de inclusión y profundización financiera que se han dado en los últimos años, y para esto en primer lugar se debe analizar qué son las microfinanzas para los habitantes en los municipios rurales, cuáles son las entidades de mayor impacto y los principales productos en su región.

En el caso particular de Colombia, las microfinanzas rurales se entienden como operaciones financieras de bajo monto, dirigidas a apalancar actividades productivas aplicando una metodología de asesoría y acompañamiento especial a clientes ubicados en municipios con vocación rural. Por lo general, las enti- 
dades públicas y privadas colombianas toman como referente las categorías de municipios que define la Ley 617 de 2000 en función del número de habitantes para catalogar o no a un municipio como rural, considerando las categorías $3,4,5$ y 6 como municipios con estructura rural, es decir, aquellos con población menor o igual a 50000 habitantes. Dicho criterio es el empleado en la presente investigación con el propósito de analizar la prestación de servicios microfinancieros rurales en el país.

A partir de un estudio detallado de los factores y variables del territorio, además de las necesidades particulares de financiación del cliente, se diseña la estructura del producto, la política de crédito y la metodología de otorgamiento, evaluación, acompañamiento y seguimiento (Salazar et al., 2015).

Así, el microcrédito rural se presenta como una herramienta que apoya y acompaña las inversiones productivas de la población rural, la cual generalmente está enfocada en la inversión y sostenimiento de proyectos y actividades agropecuarias.

Dentro de las particularidades de las necesidades de financiación de los proyectos productivos emprendidos en municipios rurales se puede destacar, tal como lo señala González (2015), que las actividades productivas en zonas rurales se encuentran en su mayoría lideradas por unidades productivas familiares, de tal forma que la inversión en el proyecto productivo está regulada por el gasto familiar, entendido como la sumatoria de recursos y erogaciones de una familia ajustada para complementar los recursos que obtiene externamente para el establecimiento del proyecto productivo.

En el caso de proyectos productivos agropecuarios, dada su periodicidad y demás características, los compromisos adquiridos con la entidad microfinanciera se saldan por medio de los ingresos totales de la unidad productiva familiar, de tal forma que la vulnerabilidad de los otros ingresos se convierte en una variable crítica de evaluación.

Tales características son de vital importancia a la hora del diseño de productos microfinancieros enfocados en el sector rural, en especial entendiendo que la mayoría de los habitantes rurales no dispone de la información mínima para un análisis de riesgo adecuado. De allí que el papel de la metodología microfinanciera aplicada sea de gran relevancia, ya que no es equiparable a los lineamientos aplicados en zonas urbanas. Por lo tanto, cuando tales aspectos se omiten y se emulan procedimientos de entidades financieras comerciales (no microfinancieras) se pierde la metodología de apoyo y acompañamiento a la inversión productiva y se empieza a dibujar un proceso de financiarización dentro de la prestación de servicios microfinancieros en municipios rurales, que tal como advierte 
Bonizzi (2014), va acompañado de un proceso de crecimiento de la prestación de servicios microfinancieros por parte de instituciones financieras reguladas y de carácter comercial, que orientadas hacia el aumento de la rentabilidad causan escenarios de inestabilidad.

\section{METODOLOGÍA Y DATOS:} ¿CÓMO ABORDAR EL ESTUDIO DE LAS MICROFINANZAS RURALES EN COLOMBIA?

Con el fin de analizar el desarrollo de las microfinanzas rurales en Colombia más allá de la discusión sobre inclusión financiera, se contempla la aplicación del método de investigación cualitativo, complementado con el análisis de indicadores que permitan estudiar el funcionamiento y evolución de las microfinanzas rurales en el país a profundidad. Con este propósito, se construye la Encuesta sobre uso de productos y servicios microfinancieros en zonas rurales 2018, para ahondar en la percepción local y regional sobre los servicios microfinancieros. El análisis en mención se complementa a través de entrevistas de profundización aplicadas a expertos en el campo microfinanciero colombiano entre octubre de 2017 y enero de 2018.

Tabla 1. Ficha técnica Encuesta sobre uso de productos y servicios microfinancieros zonas rurales

\begin{tabular}{cc}
\hline Propósito & $\begin{array}{c}\text { Conocer la percepción de comunidades rurales } \\
\text { frente a los productos microfinancieros }\end{array}$ \\
\hline Universo & Hombres/ Mujeres mayores 18 años \\
\hline Tamaño muestra & 222 encuestas \\
\hline Método/Técnica recolección & $\begin{array}{c}\text { Cuestionario estructurado compuesto por preguntas } \\
\text { cerradas, semiabiertas y abiertas. }\end{array}$ \\
\hline Puntos muestreo & Boyacá (Motavita, Nuevo Colón, Oicatá, Paipa; Villa de Leyva) \\
Secolección/Procedi- & Muestreo aleatorio simple, con selección de \\
miento muestreo & unidades primarias de muestreo (municipios) \\
\hline Margen error & {$[1,10]$. Nivel de confianza del 95 \% (dos colas). } \\
\hline Fecha recolección & 29 noviembre 2017 - 31 enero 2018 \\
\hline
\end{tabular}

Fuente: elaboración propia

Analizar un proceso de financiarización de las microfinanzas rurales colombianas implica ver la incursión de entidades financieras comerciales en las microfinanzas entre 2009 y 2010, se basa en la expansión de nuevos segmentos de clientes con potencial de desarrollo y se denomina downscaling3. De la mano con tal ingreso se ha dado el proceso del cambio de metodología o incluso de la pérdida de esta en la prestación de servicios microfinancieros en zonas rurales

3 Downscaling: microfinanzas, refiere a entidades financieras comerciales tradicionales que se introducen en segmentos de microempresas de menor escala (Leyva, 2010). 
del país. La transformación formal del sistema microfinanciero se caracteriza además por un proceso upgrading 4 , es decir, mediante una evolución en la cual instituciones como las organizaciones no gubernamentales (ONG) que brindan servicios financieros a personas con bajos ingresos y microempresas, se transforman en una institución regulada y sustentable al nivel de una entidad bancaria formal.

En menor medida, a causa de la coyuntura de posacuerdo, se ha evidenciado un proceso de transformación de tipo Greenfields ${ }^{5}$, el cual da lugar a la conformación de instituciones que dependen de las donaciones y subsidios recibidos para atender exclusivamente a las poblaciones con bajos niveles de ingresos.

En relación con este proceso, se destaca la labor de entidades de cooperación internacional. Tal es el caso de la iniciativa de Finanzas Rurales -USAID-6, la cual busca aumentar la inclusión financiera en 197 municipios del país, por medio de la coordinación y articulación de esfuerzos públicos y privados para promover el acceso al crédito, el financiamiento de cadenas de valor y la bancarización en zonas rurales y urbanas, fomentando la educación financiera y brindando asistencia técnica y acompañamiento a las entida- des financieras, para que estas tengan mayor presencia territorial, aumenten sus clientes y potencien los que tienen, mejoren rentabilidad con un modelo sostenible e innovador y mejoren la calidad de su cartera.

Opportunity Colombia es una entidad regulada que atiende poblaciones rurales a través de la alianza estratégica con USAID. La iniciativa de finanzas rurales ha permitido a entidades como Opportunity incursionar en municipios rurales con metodologías microfinancieras como es la banca comunal. Esta metodología hace referencia a créditos asociativos (15-20 personas) para apoyo de actividades productivas, que tienen una garantía solidaria que funciona dentro del grupo donde todos son codeudores de todos; los montos son pequeños (desde $\$ 150000$ ) y son créditos desembolsados a cuatro meses, con pagos semanales (García, 2017).

Desde entidades públicas, como el Banco Agrario, también se ofrecen líneas grupales como un producto microfinanciero que busca consolidar grupos de microempresarios para facilitar el acceso a créditos y promover el ahorro. De acuerdo con Barrero (2018), en el Banco Agrario una de estas líneas se denomina Núcleos Solidarios, son agrupaciones (7 o más personas) que se

$4 \quad$ Upgrading: tecnicismo empleado en las microfinanzas frente al proceso de crecimiento y expansión de la entidad y de su oferta de servicios, lo cual va de la mano con su paso hacia entidades supervisadas o reguladas (Leyva, 2010).

5 Greenfields, refiere a la creación de entidades financieras especializadas, las cuales inician su gestión generando nuevas opciones especialmente para los segmentos menos favorecidos (Leyva, 2010).

6 El Banco Mundial y USAID comenzaron a impulsar con fuerza el concepto de microfinanzas para reducir la necesidad de subsidios insistiendo en las ventajas de las microfinanzas con ánimo de lucro. 
consolidan para facilitar el acceso a crédito y fomentar el ahorro con la visión de que, a mayor calidad de selección de los miembros y capacitación de los integrantes, mayor calidad de cartera y estabilidad del grupo.

A pesar de los casos expuestos, los resultados de la encuesta realizada indicaron que la implementación de

metodología de banca comunal en el campo colombiano es mínima; para el caso de los municipios encuestados, tan solo el $6 \%$ de las personas había solicitado créditos de manera grupal y de estas el $43 \%$ calificaba esta opción como una buena o incluso excelente experiencia en comparación con un crédito individual, mientras que el $57 \%$ restante lo calificaba como regular o malo (figuras 1 y 2).

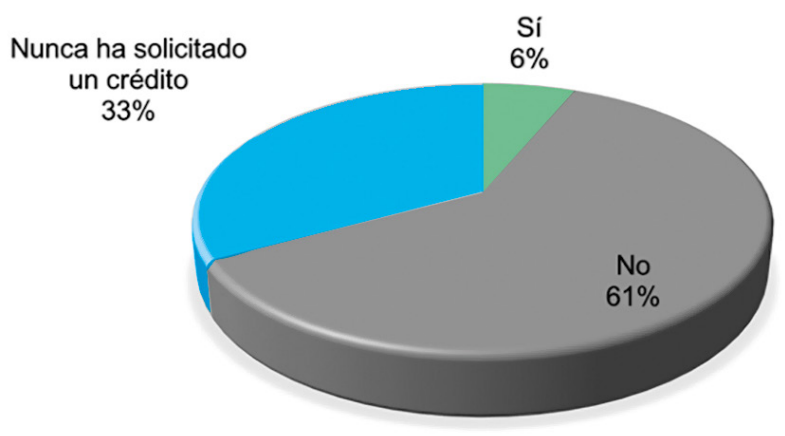

Figura 1. Créditos grupales en los municipios rurales encuestados: ante la pregunta si alguna vez había tenido un crédito grupal.

Fuente: encuesta sobre uso de productos y servicios microfinancieros en zonas rurales, 2018.

Reconociendo la presión social como uno de los factores problemáticos de las microfinanzas financiarizadas, resulta necesario analizar su impacto desde la perspectiva de la demanda para el caso rural colombiano; sin embargo, la presión social indebida dentro de créditos grupales no caracteriza la práctica microcrediticia rural en el país, ya que la aplicación de banca comunal no está tan extendida en las áreas rurales de Colombia en comparación con otras economías emergentes. Por lo tanto, se puede anotar que los posibles efectos negativos que puede acarrear dicha figura grupal no son evidenciables, por el momento, en los municipios rurales colombianos. 


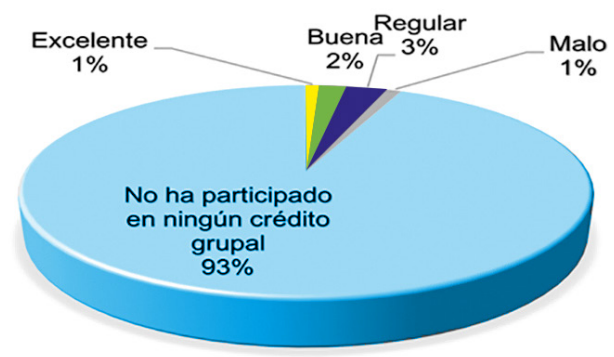

Figura 2. Calificación de la experiencia de haber tenido créditos grupales dada en los municipios rurales.

Fuente: Encuesta sobre uso de productos y servicios microfinancieros en zonas rurales, 2018.

Por otro lado, al analizar como factor de un proceso de financiarización el empleo de prácticas coercitivas en municipios rurales de Colombia por parte de entidades microfinancieras, no se tiene reporte en los últimos años del empleo de presiones indebidas. Tal como lo evidencia la crisis microfinanciera en Andhra Pradesh, las prácticas coercitivas son las manifestaciones más graves y últimas en darse en el fenómeno de financiarización.

De acuerdo con las estadísticas de quejas consolidadas por parte de la Superintendencia Financiera y del Defensor del Consumidor, entre 2013 y 2017 las quejas por procedimientos y honorarios de cobranza en microcrédito fueron inferiores al $0.14 \%$ del total de quejas. En tal lapso, el año 2015 fue en el que se presentaron mayor número de quejas al respecto, con un total de 1492 quejas (Superintendencia Financiera de Colombia [SFC], 2018). Sin embargo, dado el total de usuarios, este porcentaje no representa una señal de alarma.
Por otra parte, es destacable que el bajo nivel de cartera vencida se logra gracias al compromiso personal de los usuarios, tal como se evidencia en los resultados de las encuestas realizadas, pues este motivo fue escogido por el $92 \%$ de los habitantes rurales encuestados, mientras que la presión por parte del acreedor tan solo representó un motivo para pagar las deudas para el $6 \%$. Ligado a esta motivación se destaca que el porcentaje de habitantes rurales encuestados que reportan haber quedado alguna vez en mora corresponda únicamente al $15 \%$, lo cual se refleja en que el índice de cartera vencida de entidades como el Banco Agrario para uno de los municipios encuestados (Nuevo Colón, Boyacá), corresponda a $1.7 \%$, un excelente indicador que, de acuerdo con Barrero (2018), se debe a la buena organización regional, a evitar la colocación a población flotante y al conocimiento del cliente. 
El compromiso personal de los habitantes rurales, sumado a las políticas en contra del sobreendeudamiento que llevan a cabo las entidades microfinancieras, se refleja en que solo el $7 \%$ de los encuestados reporten haber tenido o tener más de tres créditos en un mismo periodo de tiempo (Figura 3), lo cual coincide con el límite de cré- ditos aceptados por parte de entidades como Bancamía (2017) y Opportunity Colombia. Lo anterior refleja que, en el ámbito rural, las entidades microfinancieras y sus clientes evitan escenarios de sobreendeudamiento y, en consecuencia, se prevén escenarios críticos característicos de las microfinanzas financiarizadas.

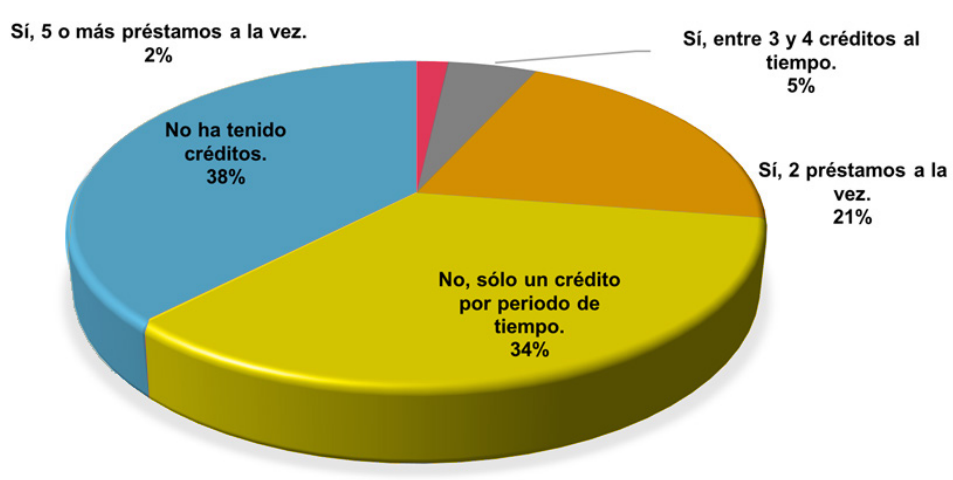

Figura 3. Número de créditos por usuario en los municipios rurales encuestados.

Fuente: Encuesta sobre uso de productos y servicios microfinancieros en zonas rurales, 2018.

Frente a los altos cobros sobre los servicios microfinancieros, se debe señalar que estos pueden ser explicados desde dos perspectivas para el caso rural, o bien corresponden al alto riesgo inherente al préstamo a sectores como el agropecuario, o se deben a los altos requerimientos de retorno de los interesados en las instituciones microfinancieras. Para Colombia se puede observar que las entidades no superan la tasa de usura estipulada y que los niveles de ingreso están destinados al cubrimiento de los gastos de operación; tal como lo señala Achury (2017), en las zonas rurales, más que el riesgo, son los costos operativos los que determinan el mayor porcentaje cobrado a los usuarios, lo anterior está relacionado con que los costos debidos a las pérdidas en los créditos son relativamente bajos, especialmente en comparación con los bancos comerciales y la cartera vencida en zonas urbanas.

Según Estrada (2017), la tasa que maneja el microcrédito es justa, pues es un servicio costoso, dado que los gastos 
operativos de microcrédito rural oscilan alrededor del $28 \%$, sin contar riesgos. Incluso, entidades como Opportunity Colombia reportan haber tenido pérdidas recurrentes en su proceso de conciliar su misión social y ser a la vez una entidad regulada. En este sentido, las altas tasas de interés serían una respuesta a los altos costos de operación, en lugar de responder a los riesgos o a las ganancias en el contexto microfinanciero rural colombiano.
Frente a estos argumentos, la percepción de los habitantes rurales encuestados es muy dividida; tal como se puede observar en la Figura 4, al preguntar en comparación con las tasas de interés de otros servicios, para el $28 \%$ de los encuestados las tasas de los servicios microfinancieros son adecuadas, mientras que para el $29 \%$ son inadecuadas. No obstante, el 39\% considera que no da su opinión pues no conoce a fondo el tema.

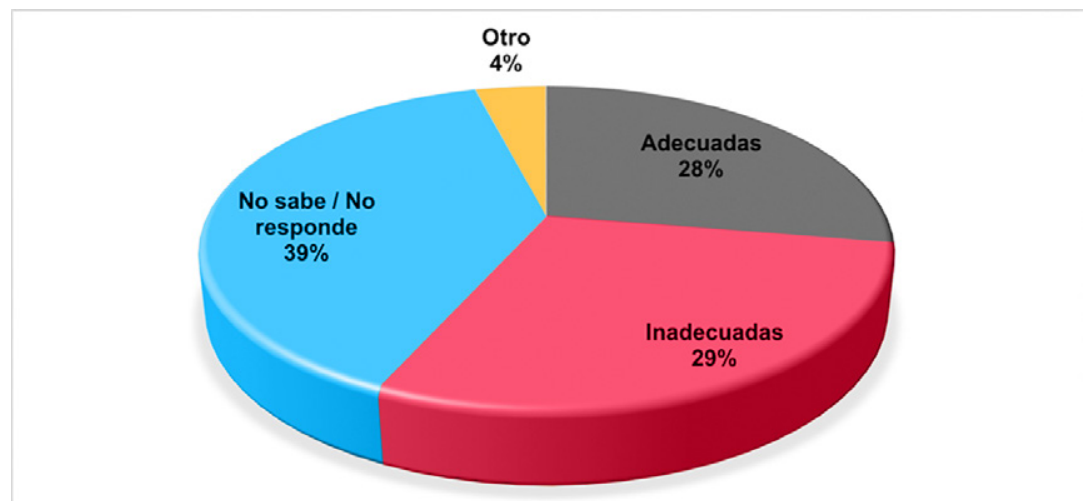

Figura 4. Percepción en los municipios rurales encuestados sobre la tasa de interés de los servicios microfinancieros.

Fuente: Encuesta sobre uso de productos y servicios microfinancieros en zonas rurales, 2018.

Acerca de los intereses rentísticos sobre la prestación de servicios microfinancieros, se debe analizar que en el caso colombiano para los bancos de nicho, como sucede con entidades como Bancamía (2017), los accionistas que son a su vez entidades sin ánimo de lucro, se presentan como una de las principales fuentes de recursos que permiten financiar sus actividades. Tal como lo señala García (2017), los altos costos de los servicios microfinancieros, ligados a la regulación en la tasa de interés, no permiten a muchas entidades no reguladas por la Superintendencia Financiera ser sostenibles financieramente, por lo cual resulta necesario convertirse en entidad regulada para, de este modo, poder hacer una mezcla de productos que permita balancear financieramente la operación y posición financiera. 
Particularmente, las ONG microfinancieras no pueden captar dinero del público $\mathrm{y}$, por lo tanto, no pueden ofrecer un portafolio diversificado, lo cual hace que el fondeo sea muy costoso, ya que deben recurrir a préstamos de los bancos comerciales a tasas comerciales que reducen los márgenes. Mientras que cuando ya se es banco regulado se empieza a ofrecer el servicio de captación, lo cual permite que cerca del $38 \%$ del fondeo de los bancos de nicho provenga del ahorro y de los CDT, lo que ha permitido desconcentrar el fondeo proveniente de bancos comerciales (Achury, 2017).

Otra estrategia que ha sido útil para balancear financieramente a tales entidades ha sido la emisión de bonos, lo cual para entidades como Bancamía (2017) ha servido como una importante fuente de recursos que ha permitido disminuir sus costos por medio de la reducción del fondeo proveniente de bancos comerciales. Esta reducción de costos, según Achury (2017), facilita que las tasas de microcrédito permanezcan por debajo de los niveles de usura y se continúe reforzando las tecnologías de acompañamiento microfinanciero.

Teniendo en cuenta lo anterior, las fallas en la prestación de servicios microfinancieros pueden presentarse por parte de bancos comerciales tradicionales, que incursionan en este nicho del mercado sin la prestación adecuada de asesoría y acompañamiento al usuario, es decir, sin la verdadera aplicación de la metodología microfinanciera. Si bien no se puede señalar evidencia de un cegado interés rentístico en estas prácticas, sí representa un punto de vulnerabilidad para la población que ha generado sobreendeudamiento o fracaso en la inversión productiva7. Pues tal como se señaló previamente, es precisamente el distanciamiento de los clientes el principal catalizador de las crisis microfinancieras y, en consecuencia, uno de los principales indicadores de un proceso de financiarización microfinanciera.

A la par con la carencia de metodología microfinanciera, otro aspecto que caracteriza la financiarización es el uso de recursos en actividades no productivas, es decir, si se ha destinado el monto del microcrédito en gastos de consumo o como libre inversión, hecho que desdibuja la razón de ser de las microfinanzas. Para el caso colombiano, ciertas entidades prestadoras de microcrédito contemplan no solo la destinación de los montos a capital de trabajo e inversión en activos fijos del negocio, adecuaciones o remodelaciones de local o vivienda donde funcione la microempresa, sino también contemplan inversiones mixtas que incluyen consumo. Sin embargo, este no es el

$7 \quad$ De acuerdo con el índice de señales de alerta temprana de sobreendeudamiento (OID), elaborado por el Centro para las Microfinanzas de la Universidad de Zúrich y presentado por Kappel et al. (2011), Colombia se clasifica en nivel medio a alto de riesgo de alarma de futuras crisis de sobreendeudamiento, en parte debido a la existencia de problemas de pago a causa de razones distintas al sobreendeudamiento, como factores relacionados con fluctuaciones inesperadas de los precios que están fuera del control tanto del deudor como del acreedor. 
común denominador e incluso dentro de las políticas de entidades microfinancieras que aplican metodología microfinanciera y cuya misión tiene su pilar en temas sociales, se puede observar que la colocación se destina exclusivamente a inversión productiva.

Desde la perspectiva de la demanda, en los municipios rurales encuestados, al preguntar en qué destina o destinaría el monto de un crédito, el $35.4 \%$ de las respuestas fue a vivienda, seguido por el $28.4 \%$ que contestó que destinaría dicho monto a inversión productiva, el $17.5 \%$ señaló que lo destina o destinaría a consumo, el $14.7 \%$ a educación y el porcentaje restante señaló que a otro destino.

Precisamente, el apoyo a la inversión productiva en el campo colombiano ha permitido que entidades microfinancieras presenten cifras de expansión de cartera del microcrédito iguales al $37 \%$ (Cooperativa Financiera de Antioquia [CFA], 2017), consolidándose como la cartera de mayor expansión en los últimos años, donde el desarrollo de la línea de microcrédito agropecuario destinado a suplir la necesidad de capital de trabajo inmediato de las personas que desarrollan actividades agropecuarias en el sector rural con características muy informales ha tenido una especial relevancia.

Por otra parte, un aspecto de difícil medición cuantitativa, pero que por medio del acercamiento cualitativo es posible determinar, es el hecho de que entidades que no brindan acompañamiento cobren comisión de microcrédito cuando tan solo ofrecen crédito de bajo monto sin aplicar tecnología microcrediticia, lo cual hace que se cobren tasas de microcrédito sin ser realmente este el servicio ofrecido. Sin embargo, la ley permite el uso de la comisión sin hacer distinciones con respecto a la aplicación o no de una metodología microfinanciera. Por lo tanto, resulta necesario reglamentar la ley de la comisión y la comitiva pertinente, de tal manera que se definan unos mínimos frente a los esquemas de acompañamiento y seguimiento, ya que no basta el monto de la transacción para que se considere como un servicio microfinanciero.

Cuando solo se aprecia el monto, se está distorsionando el concepto de microfinanzas esbozado desde la fundación del Grameen Bank y se está orientando hacia un propósito comercial y no hacia el alivio de la pobreza ni al impulso productivo de las personas sin acceso al sistema financiero tradicional.

Teniendo en cuenta las limitaciones de medición de la implementación de la metodología microfinanciera desde el lado de la oferta, la percepción por parte de la demanda se consolida como un indicador relevante a la hora de analizar este aspecto. Al respecto, de acuerdo con lo reportado en los municipios rurales encuestados, solo el $15 \%$ de las personas señalaron no haber recibido ningún tipo de acompañamiento ni ase- 
soría al adquirir un producto financiero, con respecto a aquellos que sí lo recibieron, el $74 \%$ indicó que recibió asesoría únicamente al momento de adquirir el servicio (Figura 5), lo cual muestra una notable falla en la implementación de la metodología microfinanciera, pues esta supone el acompañamiento a la iniciativa productiva y la asesoría para que el proyecto sea viable, por lo cual si solo se está brindando acompañamiento en la adquisición del producto o servicio microfinanciero, se está dejando huérfano al productor o microempresario, lo que desencadena fallas en el desarrollo del proyecto productivo que pueden elevar el nivel de riesgo al afectar el deterioro de la cartera.

El distanciamiento entre la entidad microfinanciera y el cliente se presenta como uno de los principales indicadores de financiarización de las microfinanzas rurales en Colombia, y requiere especial vigilancia, ya que tal aspecto, tal como se ha mencionado previamente, ha sido el catalizador de las crisis microfinancieras en países como India, Bangladesh y Zimbabue.

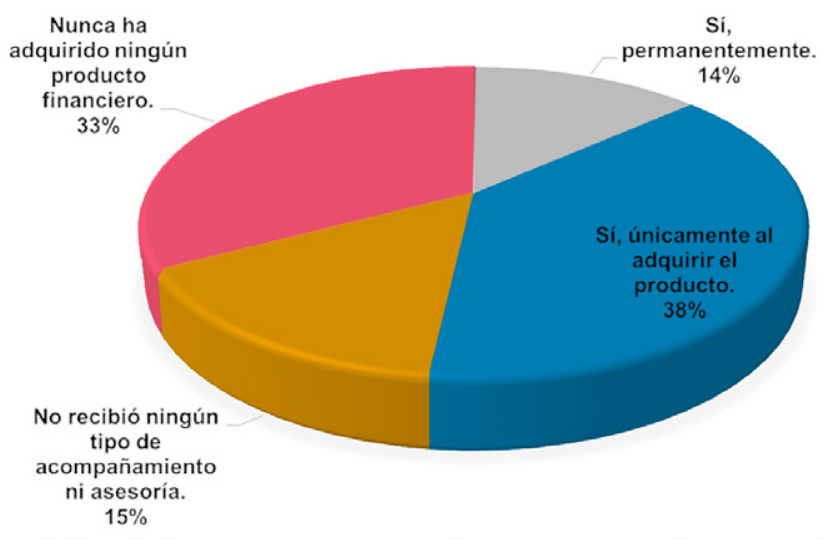

Figura 5. Percepción en municipios rurales encuestados sobre haber recibido asesoría o acompañamiento al adquirir un producto financiero.

Fuente: Encuesta sobre uso de productos y servicios microfinancieros en zonas rurales, 2018.

Otro aspecto de vital importancia al analizar la implementación de la tecnología microfinanciera es el tipo de acompañamiento o apoyo recibido, ya que la metodología implica que se vaya más allá de la educación financiera y que se aborden otros temas que permi- tan consolidar proyectos productivos sostenibles. Al respecto, de acuerdo con lo reportado en los municipios rurales encuestados, el $23.1 \%$ de las personas indicaron haber recibido educación financiera, mientras que el $17.5 \%$ señaló haber recibido educación en temas dis- 
tintos al financiero, capacitación técnica o apoyo en liderazgo y empoderamiento y valores. Sin embargo, independientemente del tipo de apoyo recibido, resulta crucial que los habitantes rurales consideren útil tal acompañamiento. De acuerdo con la opinión de los habitantes rurales encuestados, sí resulta necesario el apoyo ofrecido por parte de las entidades financieras (Figura 6).

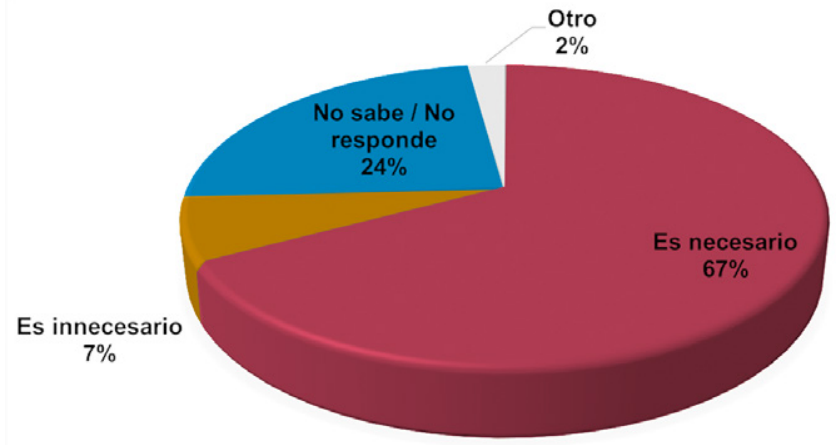

Figura 6. Percepción de habitantes rurales encuestados sobre apoyo o acompañamiento ofrecido por parte de una entidad financiera.

Fuente: Encuesta sobre uso de productos y servicios microfinancieros en zonas rurales, 2018.

Desde la perspectiva de la oferta, una forma de analizar si el crecimiento de la prestación de servicios microfinancieros ha estado o no acompañado de la implementación de la metodología microfinanciera es la comparación entre el crecimiento físico de las instituciones en los municipios rurales y el número de empleados o asesores. En la Tabla 2 se puede observar que la cobertura de servicios financieros por medio del crecimiento de corresponsales bancarios y oficinas ha estado acompañada de un crecimiento del personal prestador de los servicios financieros. En la misma tabla se puede apreciar que, a excepción del departamento de San Andrés, el crecimiento anual de oficinas de las instituciones financieras en municipios rurales es superado por el promedio de crecimiento anual de empleados, lo cual idealmente permitiría mayor acompañamiento.

Entendiendo el dinámico rol de los corresponsales bancarios en los municipios rurales del país, se debe destacar su importante crecimiento en los últimos años, tal como se puede apreciar en la Figura 7, mientras que el incremento de oficinas se ha mantenido estable y proporcional al aumento del número de empleados entre 2008 y 2014. El crecimiento de corresponsales bancarios (cb) en municipios rurales presentó variaciones superiores al $50 \%$ de acuerdo con el número de habitantes entre 2008 y 2014, como se puede apreciar en la Figura 7. 
Tabla 2. Crecimiento de corresponsales bancarios (cb), oficinas y número de empleados en instituciones microfinancieras en municipios rurales por departamento (2008-2014)

\begin{tabular}{|c|c|c|c|}
\hline Departamento & $\begin{array}{c}\text { Promedio } \\
\text { crecimiento anual } \mathrm{cb}\end{array}$ & $\begin{array}{c}\text { Promedio } \\
\text { crecimiento } \\
\text { anual oficinas }\end{array}$ & $\begin{array}{l}\text { Promedio } \\
\text { crecimiento anual } \\
\text { empleados }\end{array}$ \\
\hline Amazonas & $40 \%$ & $6 \%$ & $8 \%$ \\
\hline Antioquia & $74 \%$ & $3 \%$ & $7 \%$ \\
\hline Arauca & $71 \%$ & $2 \%$ & $15 \%$ \\
\hline Atlántico & $89 \%$ & $4 \%$ & $7 \%$ \\
\hline Bolívar & $80 \%$ & $1 \%$ & $4 \%$ \\
\hline Boyacá & $48 \%$ & $1 \%$ & $4 \%$ \\
\hline Caldas & $74 \%$ & $4 \%$ & $10 \%$ \\
\hline Caquetá & $126 \%$ & $0 \%$ & $6 \%$ \\
\hline Casanare & $102 \%$ & $4 \%$ & $10 \%$ \\
\hline Cauca & $95 \%$ & $2 \%$ & $9 \%$ \\
\hline Cesar & $82 \%$ & $6 \%$ & $15 \%$ \\
\hline Chocó & $64 \%$ & $0 \%$ & $2 \%$ \\
\hline Córdoba & $65 \%$ & $7 \%$ & $17 \%$ \\
\hline Cundinamarca & $63 \%$ & $3 \%$ & $9 \%$ \\
\hline Guainía & $100 \%$ & $19 \%$ & $22 \%$ \\
\hline Guajira & $69 \%$ & $6 \%$ & $10 \%$ \\
\hline Guaviare & $76 \%$ & $0 \%$ & $19 \%$ \\
\hline Huila & $92 \%$ & $2 \%$ & $9 \%$ \\
\hline Magdalena & $73 \%$ & $0 \%$ & $4 \%$ \\
\hline Meta & $72 \%$ & $2 \%$ & $14 \%$ \\
\hline Nariño & $64 \%$ & $1 \%$ & $8 \%$ \\
\hline Norte de Santander & $55 \%$ & $0 \%$ & $5 \%$ \\
\hline Putumayo & $101 \%$ & $8 \%$ & $18 \%$ \\
\hline Quindío & $76 \%$ & $1 \%$ & $2 \%$ \\
\hline Risaralda & $103 \%$ & $2 \%$ & $3 \%$ \\
\hline San Andrés & $83 \%$ & $-3 \%$ & $-7 \%$ \\
\hline Santander & $55 \%$ & $2 \%$ & $5 \%$ \\
\hline Sucre & $65 \%$ & $3 \%$ & $13 \%$ \\
\hline Tolima & $92 \%$ & $1 \%$ & $6 \%$ \\
\hline Valle del Cauca & $83 \%$ & $2 \%$ & $4 \%$ \\
\hline Vaupés & $68 \%$ & $6 \%$ & $7 \%$ \\
\hline Vichada & $78 \%$ & $3 \%$ & $53 \%$ \\
\hline
\end{tabular}

Fuente: Cobertura Financiera ELCA-Cifras Financieras (2017). 
En consonancia con lo anterior, es pertinente indicar que, de acuerdo con el Reporte de Inclusión Financiera 2016 (Superintendencia Financiera de Colombia \& Programa Banca de las Oportunidades [BdO]), el crecimiento promedio entre 2012 y 2016 en municipios rurales y rurales dispersos correspondió a $63.2 \%$ y $66.9 \%$, siendo perteneciente principalmente a los bancos; particularmente para el caso de los municipios rurales, Bancolombia registró el $14 \%$ de los corresponsales bancarios, seguido por Davivienda con el $11.4 \%$, Banco de Bogotá con el $10.7 \%$ y Banco Agrario con el $10.5 \%$. Adicionalmente, el reporte en mención destaca un crecimiento en 2016 del $22 \%$ de los asesores móviles en las zonas rurales, lo cual se presenta como una alternativa costo-eficiente de gran potencial.

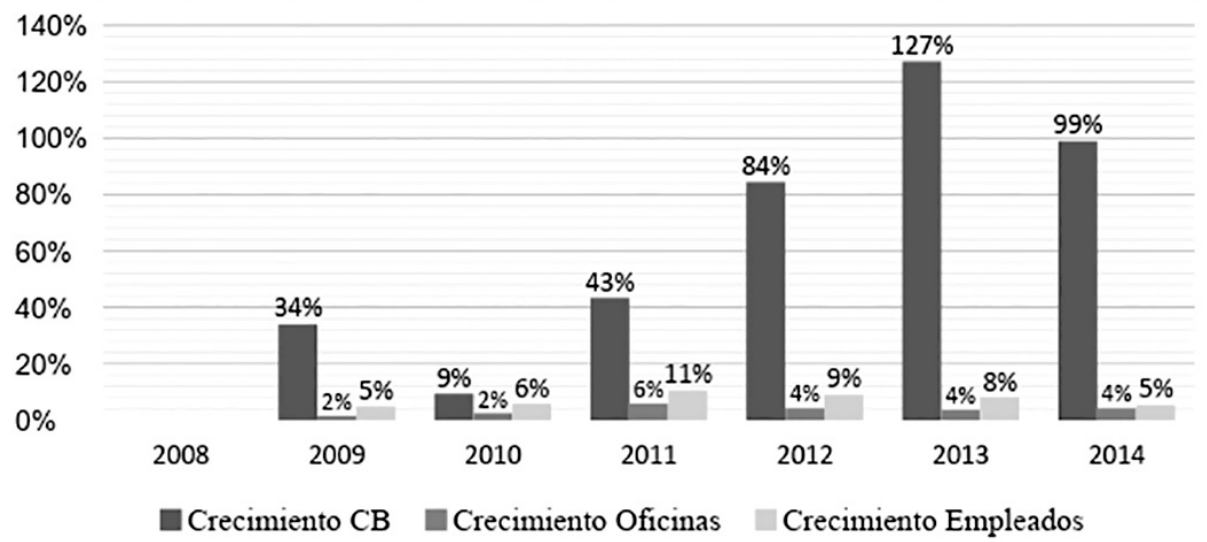

Figura 7. Crecimiento anual de cobertura financiera en municipios rurales (2008-2014)

Fuente Servicios Financieros ELCA (2017).

Por otro lado, en el periodo comprendido entre febrero de 2016 y junio de 2017, se puede observar que la prestación de servicios microfinancieros rurales presenta un crecimiento por parte de entidades reguladas o bancos comer- ciales en un $1.6 \%$, mientras que se da una notable disminución de las oficinas pertenecientes a cooperativas vigiladas por la Superintendencia de Economía Solidaria (SES) y de organizaciones no gubernamentales (Figura 8). 


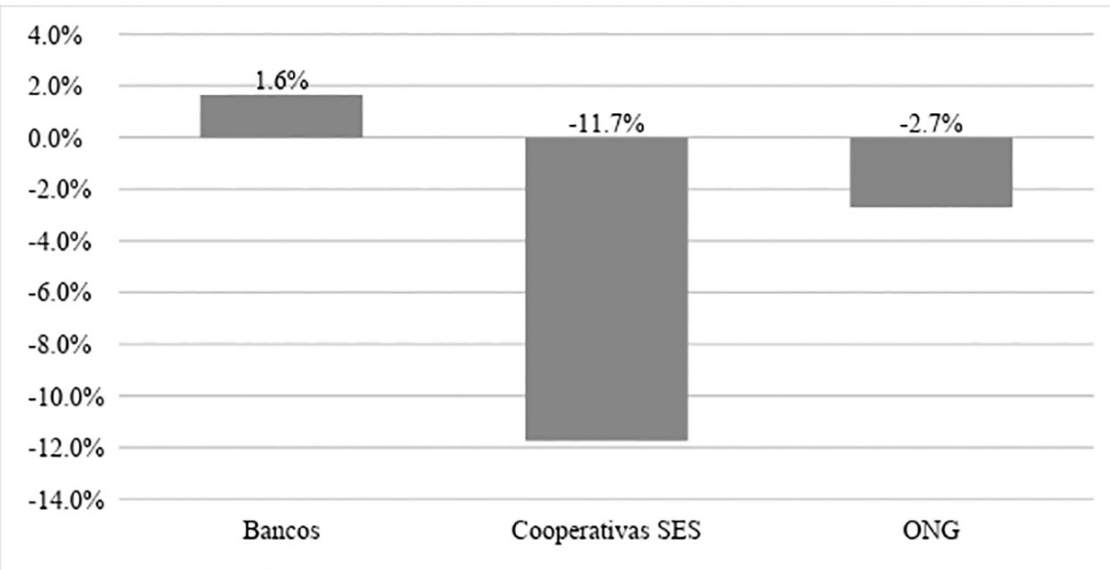

Figura 8. Crecimiento de oficinas prestadoras de servicios microfinancieros en municipios rurales (febrero 2016- junio 2017)

Fuente: Superintendencia Financiera (2018)

Tal comportamiento se explica, en parte, tal como lo expone Mondragón (2017), por la ampliación de los servicios ofrecidos que hace que las entidades en mención migren a formatos regulados, bajo los cuales están autorizados a ofrecer un portafolio de servicios más amplio y los márgenes de ganancia son más rentables.

De acuerdo con los argumentos expuestos por entidades como Opportunity Colombia o Bancamía (2017), tal migración hacia una entidad regulada, en lugar de eliminar la implementación de metodología microfinanciera, permite que se encuentre el fondeo necesario para la consecución de la metodología microfinanciera, y además se consolida como el paso necesario que posibilita la captación de dinero del público en general, lo cual sería imposible en caso de continuar como una entidad no regulada.
A pesar de la importancia de la transición hacia entidades reguladas, este aspecto enciende las alarmas y requiere un especial seguimiento, a fin de evitar que se inicie un proceso de financiarización y se migre hacia un negocio pro rentabilidad donde el cimiento social de las microfinanzas sea reemplazado por un modelo comercializado, como sucedió en México, en donde la consecuencia de una transformación upscaling se manifestó en la debilidad de los efectos de las microfinanzas en el alivio de la pobreza. Por el momento, los informes de gestión de las entidades mencionadas señalan impactos positivos de la prestación de sus servicios sobre la reducción de los niveles de pobreza; sin embargo, se requiere profundizar al respecto para realmente determinar tal efecto. 
El crecimiento señalado se evidencia también en un aumento del $25 \% \mathrm{y}$ del $12 \%$ de la cartera de microcrédito en los municipios rurales para las cooperativas financieras y entidades bancarias respectivamente, entre 2015 y 2016; y del $22 \%$ y $4 \%$ entre 2016 y 2017 . Tal incremento ha estado acompañado de una dinámica de deterioro de cartera de microcrédito para los municipios rurales, que difiere según la entidad.

Tal como se aprecia en la Tabla 3, mientras que el deterioro de la cartera ha presentado una tendencia creciente en los últimos tres años por parte de las cooperativas financieras (CF), con un crecimiento del deterioro de la cartera de microcrédito del $46 \%$ entre 2015 y 2016 , y del $27 \%$ entre 2016 y 2017 , en el caso de los bancos para este mismo periodo se ha dado un comportamiento variable, entre 2015 y 2016 se presentó un descenso del $10 \%$, mientras que entre 2016 y 2017 se dio un incremento del $9 \%$. Se debe resaltar que el deterioro en los años señalados corresponde al $5 \%$ de la cartera de microcrédito para los bancos y del $10 \%$ para las CF, lo cual es una señal de alerta que requiere mayor seguimiento por parte de la SFC.

Tabla 3. Deterioro microcrédito en municipios rurales (COP)

\begin{tabular}{cccc}
\hline $\begin{array}{c}\text { Periodo (con fecha de corte } \\
\text { hasta el mes de septiembre) }\end{array}$ & $\mathbf{2 0 1 5}$ & $\mathbf{2 0 1 6}$ & $\mathbf{2 0 1 7}$ \\
\hline $\begin{array}{c}\text { Deterioro microcrédito CF } \\
\text { Deterioro microcrédito bancos } \\
\text { Variación de deterioro } \\
\text { microcrédito CF }\end{array}$ & $\$ 2.787 .355 .158$ & $\$ 4.070 .418 .603$ & $\$ 5.152 .910 .205$ \\
$\quad \begin{array}{l}\text { Variación de deterioro } \\
\text { microcrédito bancos }\end{array}$ & 84.861 .266 .790 & $\$ 257.345 .236 .345$ & $\$ 281.266 .757 .746$ \\
$\begin{array}{c}\text { Deterioro como porcentaje } \\
\quad \text { de la cartera CF }\end{array}$ & $8 \%$ & $-10 \%$ & $27 \%$ \\
$\begin{array}{c}\text { Deterioro como porcentaje } \\
\text { de la cartera bancos }\end{array}$ & $6 \%$ & $10 \%$ & $9 \%$ \\
\hline
\end{tabular}

Fuente: : elaboración y cálculos propios con base en SFC (2018). 
El deterioro de cartera para el caso rural se debe en gran parte a las particularidades del microempresario rural $^{8}$, el cual se caracteriza por la diversificación de su ingreso y la carencia de garantías comerciales idóneas para las entidades bancarias, por lo cual el diseño y la aplicación de la metodología microfinanciera en el sector rural requieren ser muy sensibles a tales particularidades, pues básicamente, dado el escenario colombiano actual y la caracterización de la microfinanzas rurales en el mismo, se puede concluir que de la aplicación de tal metodología depende si se puede o no catalogar a las microfinanzas rurales como una herramienta virtuosa de financiamiento o si, por el contrario, se está desdibujando su cimiento social $y$ entrando en un incipiente proceso de financiarización.

Finalmente, desde la perspectiva de los habitantes rurales encuestados, se puede apreciar que a pesar de las falencias en la prestación de los servicios microfinancieros, una amplia mayoría considera que estos productos y servicios son necesarios para poder realizar actividades productivas, lo cual va en consonancia con el objetivo de inclusión financiera y misión social que promueve la tecnología microfinanciera (Figura 9).

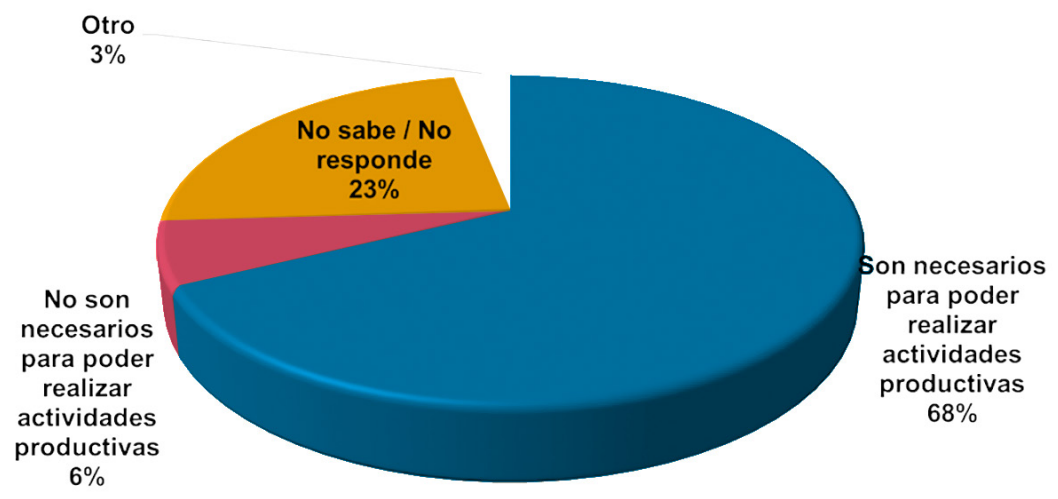

Figura 9. Opinión en los municipios rurales encuestados sobre los productos microfinancieros.

Fuente: Encuesta sobre uso de productos y servicios microfinancieros en zonas rurales, 2018.

8 De acuerdo con Asomicrofinanzas (2013), solo el $30 \%$ de los ingresos del microempresario rural proviene de la agricultura, mientras que el $70 \%$ restante proviene de su salario, remesas, comercio u otros. Las condiciones socioeconómicas de baja escolaridad, bajos ingresos, sin registros contables o rudimentarios caracterizan al microempresario rural, pero adicionalmente la mujer desempeña un papel importante en la toma de decisiones y se compromete con la asignación de créditos que le den a la unidad productiva. Teniendo en cuenta lo anterior, las entidades financieras restringen el ingreso de clientes mediante perfilamientos tales como: edad entre los 21 y 65 años; persona natural con diferentes ingresos no necesariamente agropecuarios, con sitio fijo de trabajo, finca con título o por tradición, se minimiza el riesgo si el cliente tiene multiactividad y más de dos años de experiencia en la actividad; la capacidad de pago está medida por la utilidad de los flujos de caja de las diferentes actividades y de acuerdo a estacionalidad (Asomicrofinanzas, 2013, citada en Castro, 2016). 
No obstante, el $41 \%$ de los encuestados señala que tales productos no son claves para salir de la pobreza, percepción que se ajusta al deber ser de estos productos, que es servir como herramienta para la inclusión financiera y el fortalecimiento productivo de las personas en situación de pobreza y que son excluidas del sistema financiero tradicional, mas no como solución prodigiosa del mercado para enfrentar las carencias económicas y sociales de la población rural.

\section{CONCLUSIONES}

Con el objetivo de que las microfinanzas rurales sirvan como un instrumento que conlleve el desarrollo sostenible del campo colombiano, resulta pertinente reconocer, señalar y corregir sus falencias, para evitar la distorsión de sus fines misionales en medio de un proceso de financiarización de las microfinanzas rurales, entendido como la conversión de los servicios microfinancieros hacia un enfoque netamente rentístico, en el cual se desdibuja la metodología microfinanciera y se abandona el apoyo a iniciativas productivas, dando lugar a escenarios de sobreendeudamiento, cobros por encima de la tasa de usura, acciones coercitivas para la recolección de cartera, entre otros aspectos que desencadenan una mayor vulnerabilidad económica y social de la población.

En líneas generales, se puede señalar que el proceso de financiarización de las microfinanzas rurales en el país radica en dos aspectos: el primero hace referencia a la conversión de organismos con genuino interés en combatir la pobreza hacia entes comerciales, los cuales, a fin de reducir costos, omiten el acompañamiento al emprendedor. El segundo aspecto se refiere a la incursión de instituciones con fines de lucro en municipios rurales con la oferta de productos de bajo monto sin ningún carácter social, hecho que propicia escenarios de sobreendeudamiento y cobro de elevadas tasas sin la contraprestación de asesoría, lo cual representa un objetivo financiero en sí mismo y no se ajusta a la definición de microfinanzas.

La financiarización de las microfinanzas rurales en Colombia es aún incipiente. No obstante, es necesario realizar especial seguimiento a las interacciones entre fondos y entidades microfinancieras que carecen de un marco regulatorio que proteja a los usuarios. Tal objetivo configura una línea futura de investigación. También la configura la necesidad de explorar la percepción de la demanda en más regiones del país, a fin de caracterizar desde esta perspectiva las dinámicas microfinancieras en otros entornos y complementar así el análisis de los indicadores de alcance nacional.

En contraste con el proceso de financiarización y en busca de consolidar una alternativa de financiamiento virtuosa, las instituciones que prestan servicios microfinancieros en municipios rurales con el interés genuino de combatir la pobreza, deben diseñar productos adecuados y especiales para la población 
objetivo e implementarlos de manera articulada con estrategias como la provisión de activos y de capital humano, que conduzcan a potenciar los beneficios del acceso al crédito.

En consecuencia, las microfinanzas deben estar orientadas por los principios de la metodología microcrediticia sobre la cual fueron construidas, es decir, por la asistencia técnica, sin desligarse del papel del Estado, en especial en escenarios como el de los municipios rurales del posacuerdo, ya que además de los esfuerzos por una mayor inclusión financiera, se debe promover que esta inclusión esté acompañada por un componente de sostenibilidad (desde la demanda) que impacte los hábitos de ahorro, consumo e inversión de la población objetivo, para fortalecer de este modo el acompañamiento hacia un incremento productivo en el campo colombiano.

En este mismo sentido, cabe destacar el papel que ha tenido el fomento de transacciones electrónicas, banca móvil y corresponsales bancarios, en el balance entre innovación y oferta de productos financieros, que ha permitido la reducción de costos operativos y ha contribuido a la implementación de mejores tasas en los servicios microfinancieros. El uso de innovaciones tecnológicas constituye un camino viable para alcanzar una tarifa asequible para los campesinos colombianos, sin sacrificar la asesoría imprescindible en la aplicación de la metodología microfinanciera.
Consolidar una nueva regulación, enfocada en la oferta de servicios microfinancieros, debe comprender, entre otros, los siguientes aspectos: la evaluación personalizada de los proyectos productivos en los que se emplea el microcrédito para, de este modo, garantizar la esencia de emprendimiento que los acompaña y fomentar la cercanía de las instituciones con sus clientes; la concreción de mecanismos flexibles en la periodicidad de los pagos de acuerdo con el negocio que se quiera crear y no de manera esquemática; el establecimiento de los lineamientos del cobro de la comisión microcrediticia que comprendan la definición de unos mínimos frente a los esquemas de acompañamiento y seguimiento; la promoción en las entidades microfinancieras de las acciones de segmentación (conocimiento de los clientes), la diferenciación de productos, el acceso a la información, la educación económica y financiera, el mayor acceso a herramientas tecnológicas y de innovación que permitan la reducción de los costos operativos y las tasas de colocación; por último, el monitoreo al comportamiento en territorio de las entidades prestadoras de servicios microfinancieros, una vez migran a entidades reguladas, con el fin de reconocer si se presentan prácticas de sobreendeudamiento, cobro de tasas excesivas, etcétera.

En definitiva, las microfinanzas rurales no son per se una solución a la pobreza, pero sí se consolidan como un instrumento a partir del cual se viabi- 
lizan y hacen sostenibles iniciativas productivas del campo colombiano, por ende, complementan las políticas de desarrollo rural y constituyen una alternativa virtuosa de financiamiento. De allí la importancia de su promoción y monitoreo para evitar la penetración de un proceso de financiarización que ocasione inestabilidad, sobreendeudamiento y profundización de las carencias en el campo colombiano.

\section{AGRADECIMIENTOS Y CONTRI- BUCIÓN DE LOS AUTORES}

El presente artículo es fruto del trabajo final de grado de la Maestría en Ciencias Económicas de la Universidad Nacional de Colombia, de la coautora Natalia Ramírez, trabajo que fue dirigido por el coautor de este artículo, profesor Diego Guevara. Los autores manifestamos especial agradecimiento a los evaluadores, profesor Stanley Malinowitz y profesor Juan Pablo Sandoval, por sus valiosos aportes y apreciaciones, y a los jurados ciegos por sus comentarios.

\section{FINANCIAMIENTO}

Este trabajo no tuvo ningún tipo de financiamiento institucional.

\section{DECLARACIÓN DE CONFLICTOS DE INTERESES}

No se presentan conflictos de intereses financieros, institucionales ni personales que puedan influir inapropiadamente en el desarrollo de esta investigación. 


\section{REFERENCIAS}

[1] Achury, M. (2017, 21 nov.). Bancamía. Entrevista por N. R. Virviescas, en Bogotá.

[2] Alfonso, M. (2015). Entidades microfinancieras: problemas cuando olvidan su misión. Estudio de tres casos. Universidad Pontificia Comillas ICAI-ICADE.

[3] Armendáriz, B. (2013, 6 sep.). "Las microfinanzas son una alternativa para los emprendedores y las nuevas empresas": Beatriz Armendáriz. Entrevista por N. R. Virviescas, en Bogotá.

[4] Bancamía. (2017). Informe de gestión sostenible. Bancamía.

[5] Barrero, M. (2018, 19 ene.). Banco Agrario. Entrevista en Nuevo Colón, Boyacá, Colombia.

[6] Bateman, M. (2013). La era de las microfinanzas: destruyendo las economías desde abajo. Revista Ola Financiera, 6(15). https://doi.org/10.22201/ fe.18701442e.2013.15.40261

[7] Beachemin, E. (2010, 12 oct.). Microfinanzas: no es la gallina de los huevos de oro. http://www.rnw.nl/espanol/article/microfinanzas-no-es-la-gallina-de-los-hue vos-de-oro

[8] Bonilla, I. (2016). Estrategias para el mejoramiento de los programas de microfinanzas en Colombia. (Tesis para optar al título de Magíster en Ciencias Económicas). Universidad Nacional de Colombia, Bogotá.

[9] Bonizzi, B. (2014). Financialization in Developing and Emerging Countries. International Journal of Political Economy, 42(4), 83-107. https://doi.org/10.2753/ IJP0891-1916420405

[10] Butcher, W., \& Galbraith, J. (2015). Microfinance Control Fraud: Poverty and Profiteering in Latin America, Forum for Social Economics. https://ssrn.com/ abstract=2667632; https://doi.org/10.1080/07360932.2015.1056203

[11] Castro, M. (2016). Elementos relevantes en la financiación de microcrédito rural desde entidades bancarias con metodología microcrediticia. (Trabajo de Grado Maestría en Gestión de Organizaciones). Universidad Militar Nueva Granada, Bogotá. 
[12] Cooperativa Financiera de Antioquia -CFA-. (2017). Informe gestión Cooperativa Financiera de Antioquia. http://www.cfa.com.co/pdf/informe_gestion_cfa_2016. pdf

[13] DANE.(2017)Pobrezamonetariaymultidimensionalen Colombia 2016.http://www. dane.gov.co/index.php/estadisticas-por-tema/pobreza-y-condiciones-de-vida/ pobreza-y-desigualdad/pobreza-monetaria-y-multidimensional-en-colombia-2016

[14] Das, V. (2013). Vijayalakshmi Das: We are vulnerable as our clients. Microcredit Summit Campaign. (L. Reed, interviewer)

[15] Estrada, D. (2017, 2 nov.). Banco de la República. Entrevista por N. R. Virviescas, en Bogotá.

[16] Estrada, D., Venegas, L., \& Zuleta, P. (2015). Desarrollo económico, crédito rural $y$ conflicto armado en Colombia. Matrix Group SAS.

[17] Finagro. (2017). Microcrédito rural. https://www.finagro.com.co/productos-y-ser vicios/microcr\% $\%$ 3\%A9dito-rural

[18] García, C. (2017, 24 nov.). Opportunity Colombia. Entrevista por N. R. Virviescas, en Bogotá.

[19] González, J. D. (2015). Enfoque sistémico para la valoración del riesgo en el sector agropecuario colombiano. Asomicrofinanzas.

[20] Guevara, D. \& Zambrano, P. (2017). La sobrevalorada ilusión de las microfinanzas y las realidades de la financiación en la economía de los sectores populares. En C. Giraldo 8ed.), Economía popular desde abajo (pp. 147-168). Ediciones Desde Abajo.

[21] Hernández, C., Cervantes, M. \& Montoya, M. (2014). ¿De verdad están las instituciones de microfinanzas dando atención a los pobres? En Pérez, Venegas \& Martínez, Modelos para la toma de decisiones en la Ingeniería Económica y Financiera: Un enfoque estocástico. Centro e Investigación Avanzado en Finanzas de la Universidad Autónoma del Estado de Hidalgo.

[22] Hudon, M., \& Sandberg, J. (2013). The Ethical Crisis in Microfinance: Issues, Findings, and Implications. Business Ethics Quaterly, 23(04), 561-589. https://doi. org/10.5840/beq201323440

[23] Kappel, V., Krauss, A., \& Lontzek, L. (2011). Sobreendeudamiento. Responsability Investments for Prosperity. 
[24] Leyva, W. (2010, 13 sep.). Upgrading, Downscaling y Greenfield en las microfinanzas. http://www.elanalista.com/?q=node/102

[25] Maes, J., \& Reed, L. (2012). State of the Microcredit Summit Campaign Report 2012. Microcredit Summit Campaign.

[26] Misión para la Transformación del Campo. (2015). Diagnóstico económico del campo colombiano. MTC.

[27] Mondragón, A. (2017, 20 oct.). Finagro. Entrevista por N. R. Virviescas, en Bogotá.

[28] Morduch, J., \& Roodman, D. (2014). The Impact of Microcredit on the Poor in Bangladesh: Revisting the Evidence. The Journal of Development Studies, 50(4), 583-604. https://doi.org/10.1080/00220388.2013.858122

[29] Perossa, M. L., \& Marinaro, A. E. (2014). Relación entre el auge de los microcréditos financieros y el alivio de la pobreza en el escenario latinoamericano. Revista Global de Negocios, 2 (4), 15-24.

[30] Polanco, L. (2011). El motivo de lucro en las microfinanzas: un estudio con instituciones mexicanas . Revista de Economía, 28(76), 9-40. https://doi.org/10.33937/ reveco.2011.21

[31] Salazar, A., Martínez, D., \& Giraldo, M. (2015). Crecimiento del microcrédito en Colombia en los años 2010-2014. (Trabajo de grado para optar el título de Especialista en Alta Gerencia). Universidad de Medellín.

[32] Sawyer, M. (2014). What is Financialization. International Journal of Political Economy, 42(4), 5-18. https://doi.org/10.2753/IJP0891-1916420401

[33] Stiglitz, J. E. (2012). El precio de la desigualdad: el 1\% de población tiene lo que el 99\% necesita. Taurus.

[34] Superintendencia Financiera de Colombia -SFC- \& Programa Banca de las Oportunidades -BdO-. (2014). Reporte de Inclusión Financiera 2013. SFC.

[35] Superintendencia Financiera de Colombia -SFC- \& Programa Banca de las Oportunidades -BdO-. (2017). Reporte de Inclusión Financiera 2016. SFC.

[36] Superintendencia Financiera de Colombia -SFC-. (2018, 19 feb.). Información consolidada anual SFC-Defensor del Consumidor Financiero-Entidades vigiladas. https://www.superfinanciera.gov.co/publicacion/11129 
